\title{
Quantitative Gene Expression by Recurrence Score in ER-Positive Breast Cancer, by Age
}

\author{
Sandra M. Swain · Raquel Nunes · Carl Yoshizawa $\cdot$ Megan Rothney \\ Amy P. Sing
}

To view enhanced content go to www.advancesintherapy.com

Received: October 12, 2015 / Published online: November 26, 2015

(c) The Author(s) 2015. This article is published with open access at Springerlink.com

\section{ABSTRACT}

Introduction: Breast cancer in young women ( $<50$ years) has been associated with an increased risk of recurrence and decreased survival compared with patients older than 50 . The objective of this analysis was to determine, from a large database of patients with early-stage breast cancer, if the Recurrence Score ${ }^{\circledR}$ result (Oncotype DX ${ }^{\circledR}$, Genomic Health, Inc, Redwood City, CA, USA) provided clinically meaningful differences in predicted risk of recurrence in younger-compared with olderpatients.

Methods: Tumor samples from patients with estrogen receptor (ER)-positive breast cancers that were successfully processed in the Genomic Health central lab between June 2004 and December 2013 for Recurrence Score and

Electronic supplementary material The online version of this article (doi:10.1007/s12325-015-0268-3) contains supplementary material, which is available to authorized users.

S. M. Swain $(\varangle) \cdot$ R. Nunes

Washington Cancer Institute, MedStar Washington

Hospital Center, Washington, DC, USA

e-mail: sandra.m.swain@medstar.net

C. Yoshizawa $\cdot$ M. Rothney $\cdot$ A. P. Sing

Genomic Health, Inc., Redwood City, CA, USA quantitative gene expression of ER, progesterone receptor (PR), and Her/2neu, were included. Descriptive statistics were used to describe the distribution of scores by age group: <40, 40-49, 50-59, 60-69, and $\geq 70$ years, nodal status, and histologic subtype. Results: Specimens from 394,031 patients $[3.3 \% \quad(n=13,029) \quad$ aged $<40$ years; $15.6 \%$ $(n=61,643)$ aged $\geq 70$ years] were included; $81.6 \%$ of patients had invasive ductal carcinoma. Nodal status was specified for 362,001 patients $(87.0 \%$ negative). Median Recurrence Score results were similar across risk groups. Low $(<18)$ - and high $(\geq 31)$ - risk Recurrence Score results were seen in $58.5 \%$ and $8.5 \%$ of patients, respectively. A greater proportion of patients aged $<40(14.1 \%)$ than $\geq 70(8.8 \%)$ years had a high-risk score. ER expression increased as a function of age and PR single-gene and invasion gene group expression were similar across age groups.

Conclusion: These data indicate that in patients with ER-positive breast cancer, age alone does not reflect the underlying individual tumor biology, suggesting that the Recurrence Score result may add potentially 
useful information for personalized treatment decisions.

Funding: Genomic Health, Inc.

Keywords: Age groups; Breast cancer; Gene expression profiling; Oncology

\section{INTRODUCTION}

Approximately, 5\% of invasive breast cancers occur in women under the age of 40 years [1] and breast cancer is the leading cause of cancer-related deaths in women between the ages of 20-39 years [2]. Overall survival (OS) rates are lower compared with those of older women [3-5].

Young age is often delineated as premenopausal (approximately $<50$ years) [6], but much of the literature defines young age as $<35$ or $<40$ years. Reports have attributed worsening prognosis of young women to biological factors, including lower estrogen receptor/progesterone receptor (ER/PR) expression $[7,8]$ or overexpression of human epidermal growth factor receptor 2 (HER2) [9]; higher incidence of triple-negative disease (TNBC; absence of PR, ER, and HER2) [10]; vascular invasion [7]; nodal status [8]; and higher grade $[5,7]$. Other reports found that age conferred a worse prognosis, irrespective of pathologic features [7], delay in diagnosis [11], or higher treatment intensity, particularly in women aged $<35$ years [12]. Therefore, young age is frequently used as an indication for recommendation of adjuvant chemotherapy.

The 21-gene assay Recurrence Score ${ }^{\circledR}$ result (Oncotype DX ${ }^{\circledR}$, Genomic Health, Inc, Redwood City, CA, USA) provides the 10-year risk of distant recurrence and predicts the likely benefit of adding chemotherapy to endocrine therapy in women with ER-positive (ER+) early breast cancer. The Recurrence Score result has now been incorporated into major clinical guidelines for treatment decisions [13-17], based on both the prognostic and predictive information the score provides. Decisions guided by the Recurrence Score result can spare women the toxic effects of chemotherapy, such as cardiotoxicity, secondary cancers, and neurotoxicity [18-27], based on the prediction of little to no benefit in patients with a low score, as well as identifying women with high risk of recurrence who are likely to benefit meaningfully from chemotherapy.

Overall, there are limited data regarding age-specific biological differences and response to therapy in young women with ER+ disease. The objective of the analyses in this paper was to determine if the Recurrence Score result provided clinically meaningful differences in predicted risk of recurrence in younger compared with older patients.

\section{METHODS}

All ER+ [ER by reverse transcriptase-polymerase chain reaction (RT-PCR) $\geq 6.5$ threshold cycle] tumor specimens that were successfully examined in the Genomic Health (GHI) central reference laboratory (as per methods previously described) [28] from June 1, 2004 through December 31, 2013 were included in these analyses. The 21-gene assay was performed according to methods previously described [29].

\section{Statistical Analysis}

Clinical data routinely submitted to GHI on the requisition includes age, nodal status [indicated as node-negative, node-positive $(\mathrm{N}+; 1-3$ 
positive nodes), or micrometastases], and tumor grade (as determined by local laboratories). All specimens were reviewed by GHI pathologists for determination of histologic subtype. Descriptive statistics were calculated for the Recurrence Score result, single genes (ER, PR, HER2), and gene groups (invasion index and proliferation index). The distribution of Recurrence Score results was analyzed according to age, histology, and nodal status. Age groups were delineated as $<40,40-49$, $50-59,60-69$, and $\geq 70$ years.

Data for categorical variables are reported as the number of percent of observations. Continuous variables are reported as the median, mean, total range, and first and third quartiles. Both categorical and continuous variables are described within each age and Recurrence Score risk group. Because of the large size of the database, even small differences across age groups were expected to lead to statistically significant but not clinically meaningful results. Therefore, all analyses were descriptive. Analyses were performed on de-identified data.

This article does not contain any new studies with human or animal subjects performed by any of the authors.

\section{RESULTS}

\section{Demographics and Characteristics of Patients}

The analysis included samples with successful Recurrence Score results from 394,031 patients in the GHI database (Table 1). More than $99 \%$ of patients were aged 25-90 years. The majority (81\%) were aged 40-69 years; 3.3\% $(n=13,029)$ were $<40$ years, and $15.6 \%(n=61,643)$ were $\geq 70$ years (Fig. 1 ). The most common histology was invasive ductal [not otherwise specified (NOS)] in $81.6 \%$ of patients. Nodal status was specified for 362,001 patients, and $87.0 \%$ ( $n=314,875$ ) were node-negative (Fig. 2).

The age spread among the patients in the GHI database $(N=394,031)$ was also compared to the age spread among patients with newly diagnosed breast cancer in the American Cancer Society (ACS) database $(N=232,340)$ [1]. Within the GHI and ACS databases, there were a similar proportion of patients aged $<40(3.3 \%$ and $4.7 \%),<50(23.0 \%$ and $21.1 \%)$, and $\geq 50$ (77.0\% and $78.9 \%)$ years, respectively.

\section{Distribution of Recurrence Score Risk Groups}

A wide range of Recurrence Score results and risk stratification was observed within all age groups (Figs. 3, 4). Overall, 58.5\% $(n=230,529)$, $33.0 \%(n=130,082)$, and $8.5 \%(n=33,420)$ of patients had a low $(<18)$, intermediate $(18-30)$, or high $(\geq 31)$ Recurrence Score result, respectively. The proportion of low- and high-risk scores was comparable across the age groups. Notably, a greater proportion of patients aged $<40$ years appear to have high Recurrence Score results compared with patients aged $\geq 70$ years $(14.1 \%$ vs. $8.8 \%)$, and the median score was slightly higher in patients $<40$ years (18) and slightly lower in all other age groups (medians for 40-49, 50-59, 60-69, and $\geq 70$-year groups were: $16,17,16$, and 16, respectively).

\section{Histologic Subtypes and Distribution of Recurrence Score Risk Groups by Age}

Ductal carcinoma NOS accounted for $81.6 \%$ of the histologic type overall and 78-85\% across the age groups with the highest proportion in the <40-year group $(84.7 \%)$ and the lowest 
Table 1 Patient characteristics

\begin{tabular}{|c|c|c|c|c|c|c|}
\hline \multirow[t]{2}{*}{ Characteristic, $n(\%)$} & \multicolumn{5}{|c|}{ Age group, years } & \multirow[t]{2}{*}{ All patients } \\
\hline & $<40$ & $40-49$ & $50-59$ & $60-69$ & $\geq 70$ & \\
\hline Patients & $13,029(3.3)$ & $77,590(19.7)$ & $117,171(29.7)$ & $124,598(31.6)$ & $61,643(15.6)$ & $394,031(100)$ \\
\hline \multicolumn{7}{|l|}{ Nodal status $^{\mathrm{a}}$} \\
\hline $\begin{array}{l}\text { All patients with } \\
\text { nodal status } \\
\text { specified }\end{array}$ & $11,983(3.3)$ & $72,265(20.0)$ & $109,202(30.2)$ & $113,593(31.4)$ & $54,958(15.2)$ & $362,001(100)$ \\
\hline Negative & $10,717(3.0)$ & $64,489(17.8)$ & $96,158(26.6)$ & $98,345(27.2)$ & $45,166(12.5)$ & $314,875(87.0)$ \\
\hline $\begin{array}{l}\text { Positive }(1-3 \\
\left.\text { positive nodes }{ }^{\mathrm{a}}\right)\end{array}$ & $823(0.2)$ & $4938(1.4)$ & $8562(2.4)$ & $10,561(2.9)$ & $7405(2.0)$ & $32,289(8.9)$ \\
\hline Micrometastases & $443(0.1)$ & $2838(0.8)$ & $4482(1.2)$ & $4687(1.3)$ & $2387(0.7)$ & $14,837(4.1)$ \\
\hline \multicolumn{7}{|l|}{ Histologic subtype } \\
\hline $\begin{array}{l}\text { Ductal carcinoma, } \\
\text { NOS }\end{array}$ & $11,041(2.8)$ & $64,843(16.5)$ & $96,668(24.5)$ & $100,874(25.6)$ & $48,114(12.2)$ & $321,540(81.6)$ \\
\hline $\begin{array}{l}\text { Lobular-classical, } \\
\text { solid alveolar }\end{array}$ & $476(0.1)$ & $4884(1.2)$ & $9032(2.3)$ & $10,972(2.8)$ & $6254(1.6)$ & $31,618(8.0)$ \\
\hline Lobular-pleomorphic & $30(<0.1)$ & $358(0.1)$ & $630(0.2)$ & $892(0.2)$ & $503(0.1)$ & $2413(0.6)$ \\
\hline $\begin{array}{l}\text { Medulary/ } \\
\text { medullary-like }\end{array}$ & $59(<0.1)$ & $207(0.1)$ & $377(0.1)$ & $328(0.1)$ & $130(<0.1)$ & $1101(0.3)$ \\
\hline Other/unknown & $1423(0.4)$ & $7298(1.9)$ & $10,464(2.7)$ & $11,532(2.9)$ & $6642(1.7)$ & $37,359(9.5)$ \\
\hline
\end{tabular}

NOS Not otherwise specified

a Less than $1 \%$ of patients have 4 positive nodes

proportion in the $\geq 70$-year group (78.1\%; Fig. 1). Lobular-classical/solid/alveolar accounted for $8.0 \%$ overall and $3.7 \%$ in the $<40$-year group with increasing proportion over the age groups to $10.2 \%$ in the $\geq 70$-year group. Lobular-pleomorphic and medullary/ medullary-like accounted for $0.6 \%$ and $0.3 \%$ overall, respectively. The distribution of Recurrence Score results within histologic subtypes was similar when further stratified by age (Fig. 5). In patients with ductal carcinoma, a lower proportion of patients aged $<40$ years (46.9\%) had low Recurrence Score results compared with patients $\geq 70$ years $(58.2 \%)$. Patients with medullary/medullary-like histology had a greater proportion with high (approximately 43\%) scores and lower proportion of low scores, and this pattern was consistent across the age groups.

\section{Distribution of Recurrence Score Results by Age and Nodal Status}

The distribution of Recurrence Score results by nodal status $(\mathrm{N}=362,001$ : node-negative, $n=314,875 ; \quad \mathrm{N}+, \quad n=32,289 ; \quad$ and micrometastases [pNmi], $n=14,837$ ) was similar when stratified by age (Fig. 2). Within each nodal group, proportionally fewer patients $<40$ years had low-risk scores compared with 

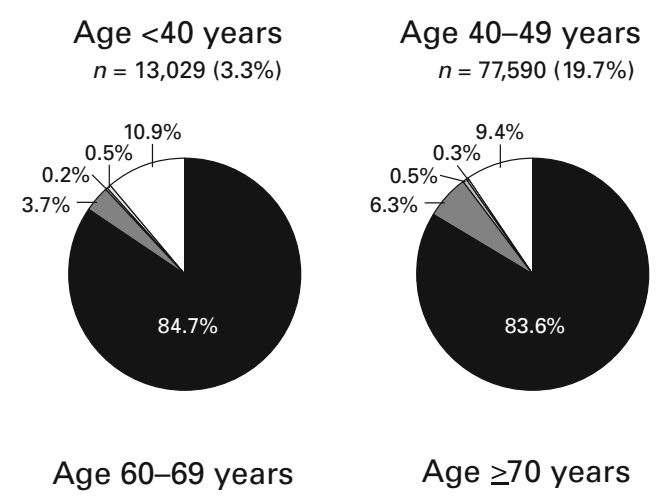

$n=124,598(31.6 \%)$
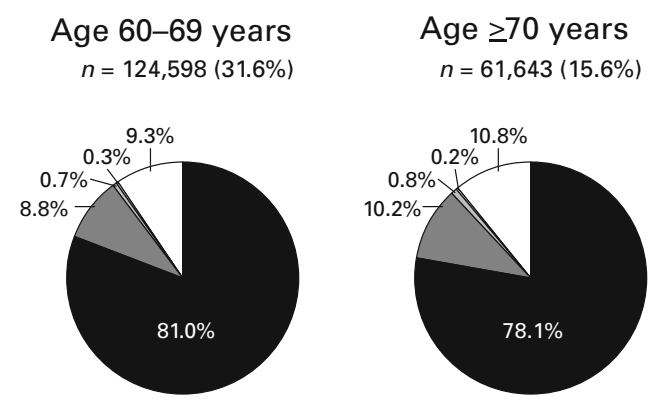

Fig. 1 Distribution of patients by age group and histologic subtype $(N=394,031)$. Histologic types captured include: Ductal (NOS); medullary/medullary-like; lobular-classical, solid, alveolar; lobular-pleomorphic; other/unknown. Each

patients $\geq 70$ years (node-negative: $48.3 \%$ vs. 59.7\%; N+: $47.4 \%$ vs. $61.7 \%$; pNmi: $51.5 \%$ vs. 63.7\%). Accordingly, in patients with micrometastases, a slightly higher proportion of patients <40 years were classified as intermediate or high risk, compared with patients $\geq 70$ years.

\section{Comparison of Quantitative Gene Expression by Age and Recurrence Score Result}

A wide range of quantitative ER and PR gene expression, as well as the proliferation index and invasion index, was observed within all age groups. ER expression increased with increasing age with a median of 9.3 in the $<40$-year group and 10.6 in the $\geq 70$-year group. There was a slight decrease in PR expression across age categories with medians of 7.8 and 7.5 ,

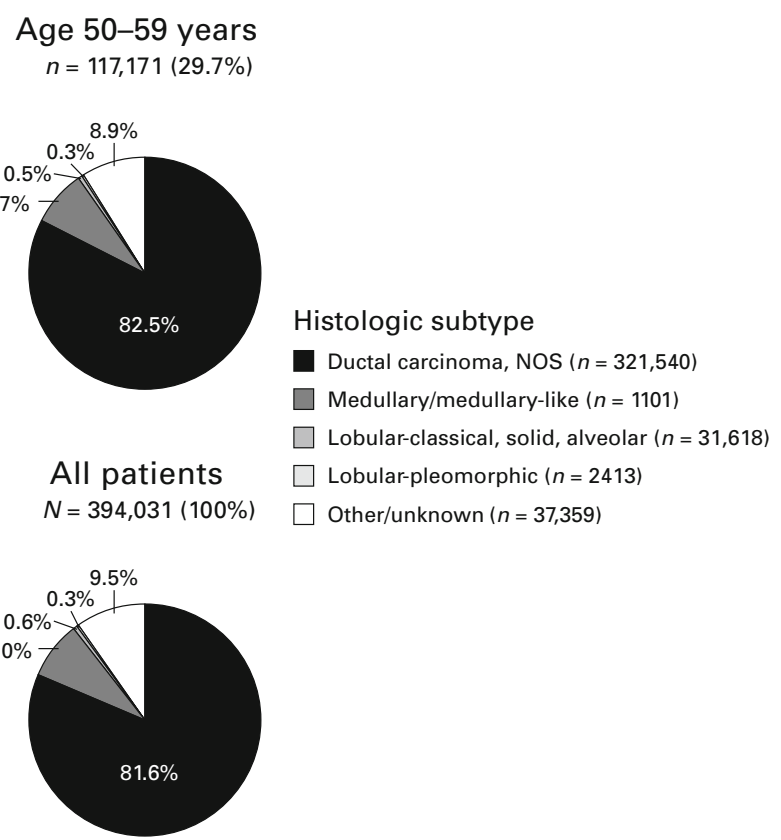

pie chart shows the proportion of histologic subtype within each age group by decade starting with $<40$ years up to $\geq 70$ years. NOS not otherwise specified

respectively. The maximum observed ER values represented more than a 100-fold greater RNA expression than the cutpoint for positivity of 6.5 in all age groups. Expression of the proliferation index and invasion index was also similar across all age groups (Fig. 6).

An analysis of the ER and PR co-expression by age group and Recurrence Score risk group is shown in Fig. 7. Across all risk groups there was a consistent pattern of increasing median ER and decreasing median PR with increasing age. Increases in median ER were most pronounced in low-risk patients (9.5 in patients aged $<40$ years to 11.0 in patients aged $\geq 70$ years), although all median ER values were substantially above the threshold for positivity (6.5). Decreasing median PR expression as a function of age was most pronounced in the high-risk group (6.0 in patients aged $<40$ years to 4.5 in patients aged $\geq 70$ years). 
(a) All patients with nodal status specified ( $N=362,001)$

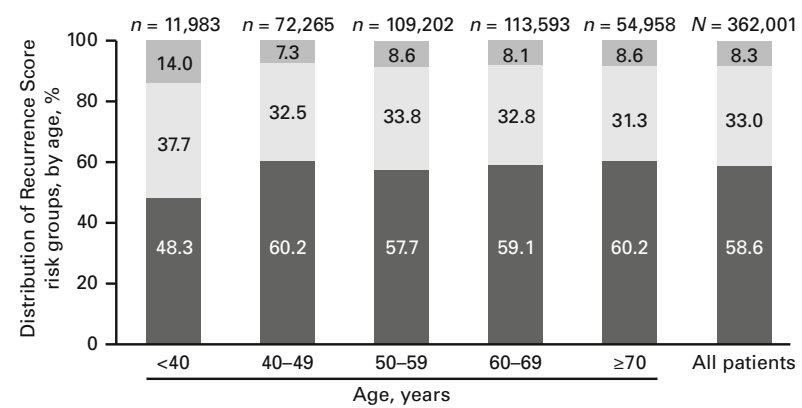

(c) Node-positive ( $N=32,289)$

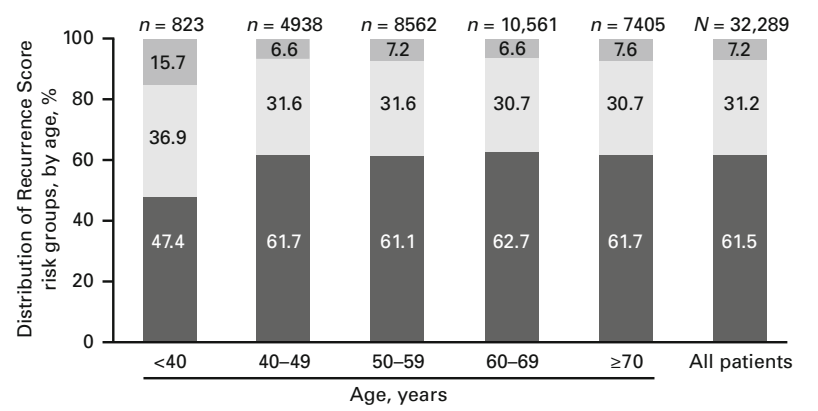

(b) Node-negative $(N=314,875)$

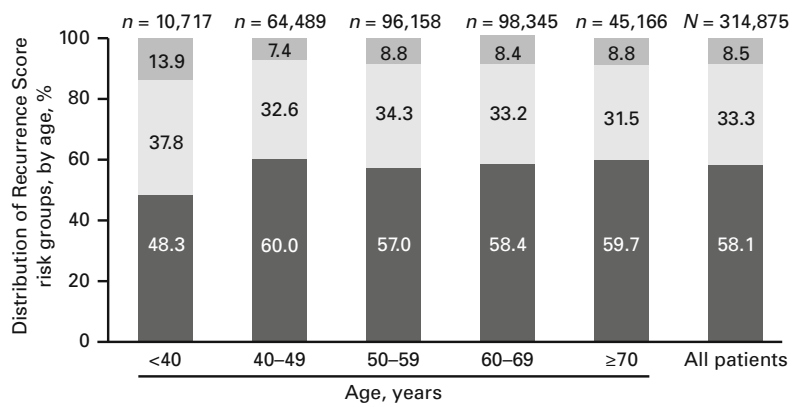

(d) Patients with micrometastases $(N=14,837)$

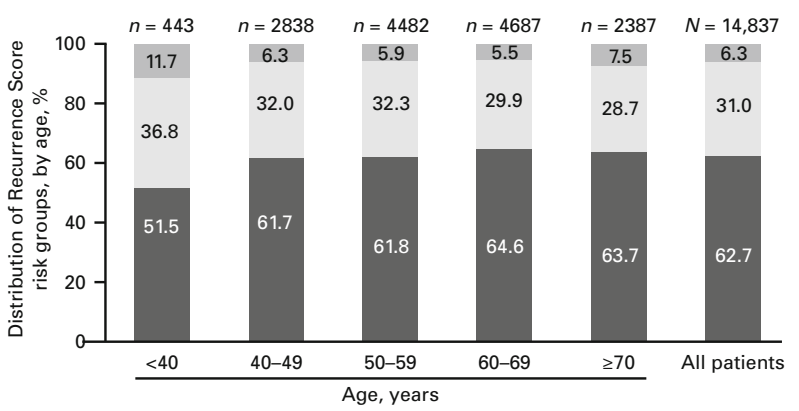

Recurrence Score risk group

High $(\geq 31)$

Intermediate (18-30)

Low $(<18)$

Fig. 2 Distribution of Recurrence Score risk group by age group and nodal status $(N=362,001)$. a Distribution across age groups in entire cohort $(n=394,031)$; b node-negative patients $(n=314,875)$; c node-positive

\section{DISCUSSION}

The 21-gene Recurrence Score result is widely used in the United States to guide the addition of adjuvant chemotherapy to endocrine therapy [30-32]. While the overall treatment paradigm has shifted substantially as a result, there continues to be a more conservative approach for treatment recommendations in younger women. As age has been traditionally associated with a poorer prognosis, young women are more often offered chemotherapy, irrespective of their Recurrence Score result. Two of the studies validating the Recurrence Score result included a lower proportion $(8.8-9.7 \%)$ of younger women $[26,33]$. patients $(n=32,289) ; \mathbf{d}$ nodes with micrometastases patients $(n=14,837)$. For $\mathbf{b}$, $\mathbf{c}$, and $\mathbf{d}$, only patients with specified nodal status were included. If field was left unmarked or if unknown, the patient was not included

However, these studies and others have consistently shown that the Recurrence Score result provides prognostic and predictive information independent of age and that there is a broad range of scores across age categories [34-37].

The GHI clinical laboratory has now processed more than 394,000 samples over a decade that includes 90,619 patients $<50$ years and $13,029<40$ years. This has enabled us to examine the distribution of the Recurrence Score results across different age categories, each of them including a large number of patients. The age range in the GHI database $(N=394,031)$ is comparable to Surveillance, Epidemiology, and End Results (SEER) with a 


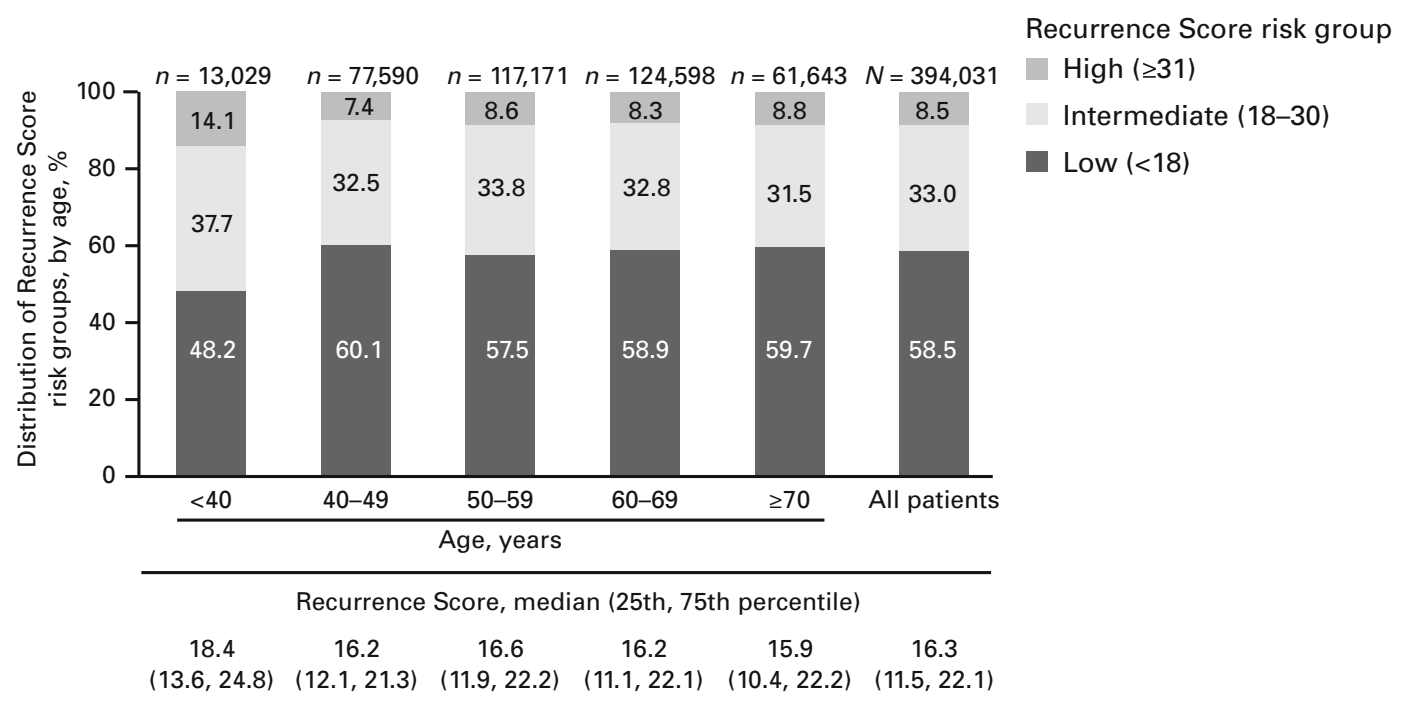

Fig. 3 Distribution of Recurrence Score risk groups by age group $(N=394,031)$. The Recurrence Score risk groups and proportion of patients within each risk and age group by decade starting with $<40$ years up to $\geq 70$ years

wide age distribution, ranging from 20 to $>85$ years [38]. Within both datasets, fewer patients were aged $<35$ or $\geq 85$ years. In the GHI dataset, we found that for all age categories, there was a range of Recurrence Score results irrespective of the histology or nodal status and that the proportion of patients in low-, intermediate-, and high-risk groups was consistent with the overall dataset. The overall distribution of Recurrence Score results in the entire GHI dataset categorized $58.5 \%$ as low risk and $8.5 \%$ as high risk. The distribution of Recurrence Score results across the age categories was consistent with the overall cohort except for the <40-year group which had a lower proportion of patients with low-risk scores $(48.2 \%)$ and a greater proportion of high-risk scores (14.1\%). Of note, the 40- to 49-year group had the highest proportion of low-risk scores (60.1\%) and the smallest proportion of high-risk scores (7.4\%). In addition, there were small differences in the median Recurrence Score results between women aged $<40$ years and those aged $\geq 70$ years (the higher median score of 18 was in patients aged $<40$ years), and the Recurrence Score result tended to decrease with advancing age. Similar observations were made when examining PR, proliferation index, and invasion index, with small absolute differences when data were stratified by age. ER values showed a larger increase as a function of age.

Other prognostic factors in addition to young age are also often used to determine course of treatment. These include histology, nodal status and older age ( $\geq 70$ years). Numerous studies have shown that young age at diagnosis is associated with poor outcome. Although tumors diagnosed in younger women often have more aggressive pathologic features, the association with poor prognosis seems to be present despite clinicopathologic factors, access to health care, and type of treatment, suggesting that breast cancer in young women may have a unique tumor biology driving their prognosis. The data regarding gene expression patterns in young women are relatively limited. A study looking at gene expression profiling in 3522 patients according to age (451 of patients were 40 years of age or younger) found a higher 

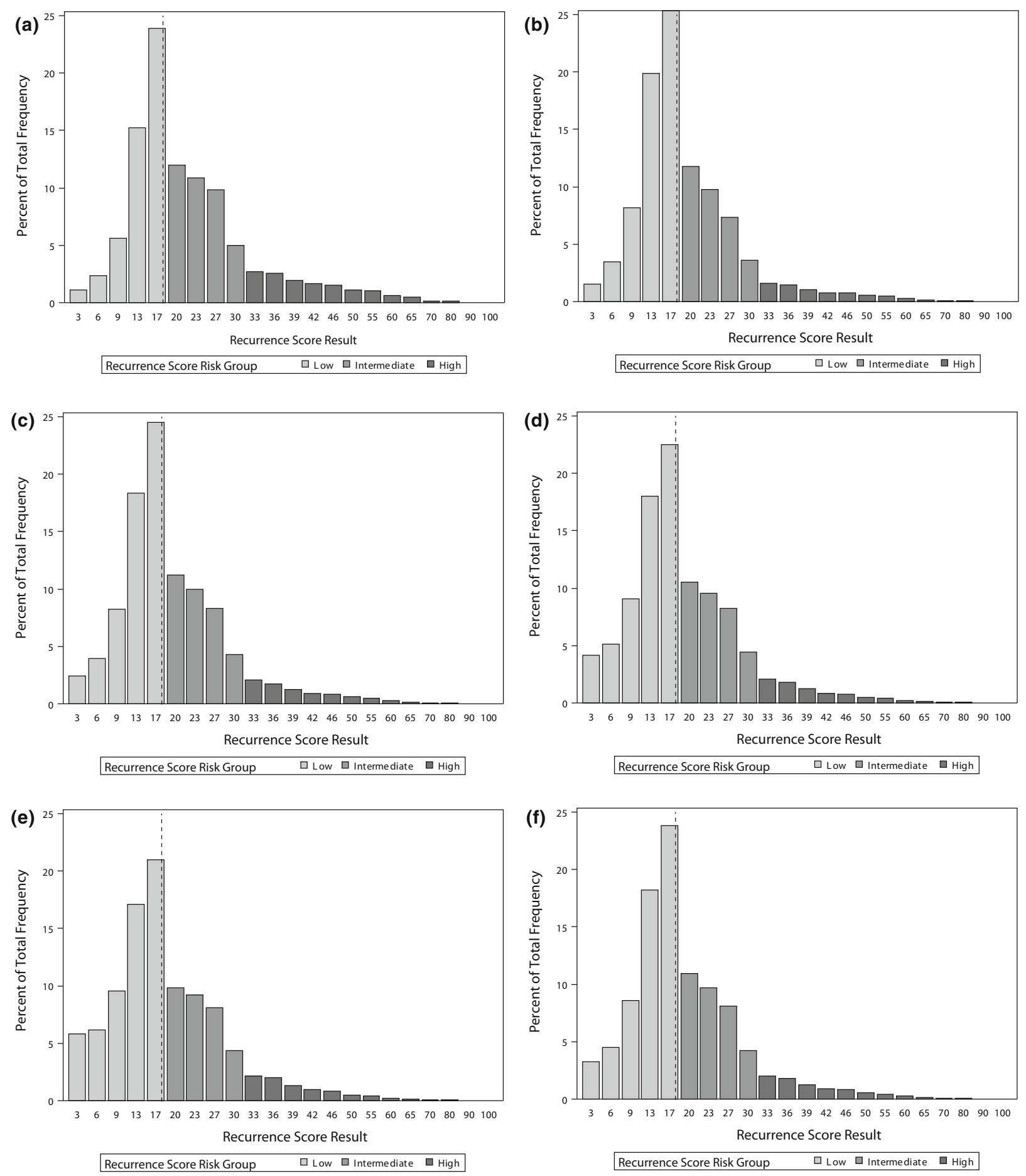

Fig. 4 Distribution of Recurrence Score results by age group $(N=394,031)$, normalized by proportion of patients in each age group (continuous Recurrence Score). a Patients aged $<40$ years $(n=13,029)$; b patients aged $40-49$ years

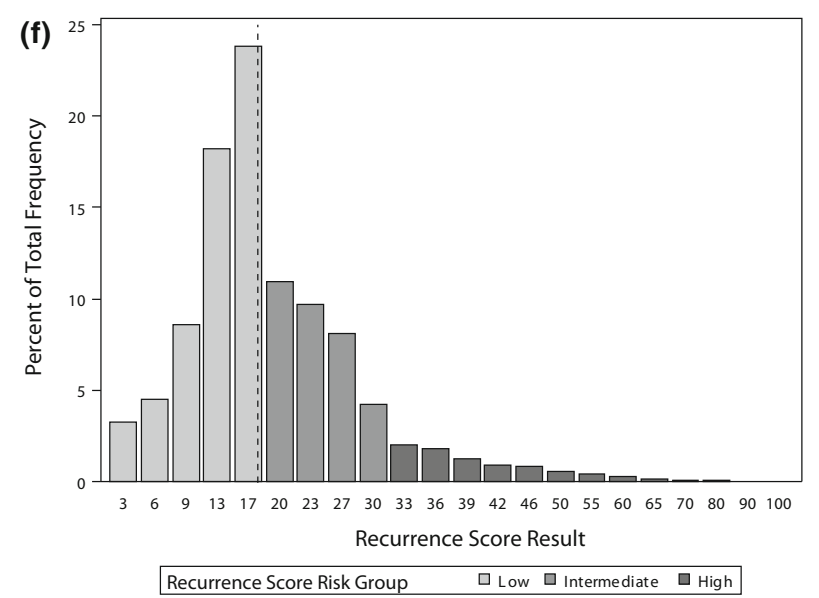

( $n=77,590)$; c patients aged $50-59$ years $(n=117,171)$; d patients aged 60-69 years $(n=124,598)$; e patients aged $\geq 70$ years $(n=61,643)$; $\mathbf{f}$ all patients $(N=394,031)$. The dashed vertical line represented the median 
(a) Ductal carcinoma, NOS $(N=321,540)$

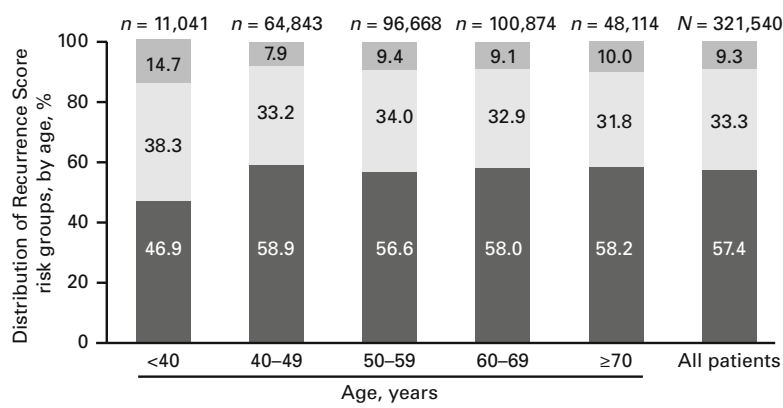

(c) Lobular-pleomorphic $(N=2413)$

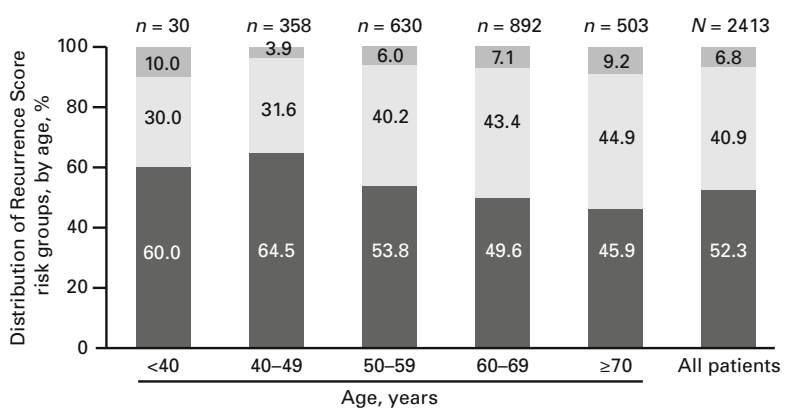

(e) Other/unknown ( $N=37,359)$

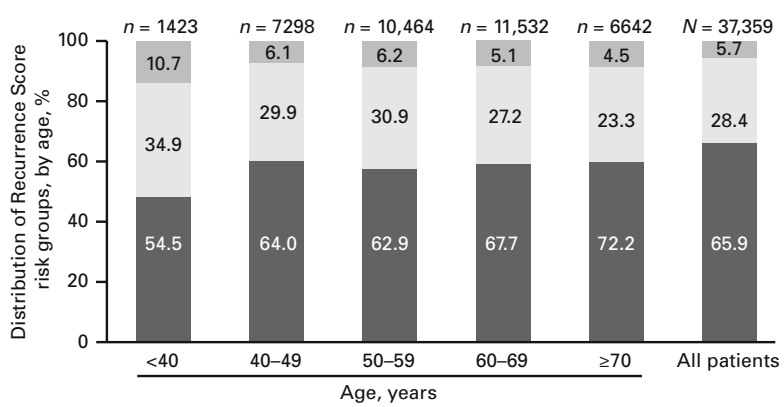

Fig. 5 Distribution of Recurrence Score risk groups by age group and by histologic subtype $(N=394,031)$. a Ductal carcinoma (82\%); b lobular-classical/solid/alveolar (8\%);

proportion of basal-like and HER2 enriched breast cancer [39]. Among young women with $\mathrm{ER} / \mathrm{PR}+$ breast cancer, there was a lower frequency of luminal A tumors. This study also showed differential expression according to age of several of the 50 genes included in the panel, regardless of tumor subtype, grade, and stage. When they looked at different prognostic gene signatures, including three proliferation-related signatures, they found that all proliferation gene signatures added significant prognostic (b) Lobular-classical, solid, alveolar $(N=31,618)$

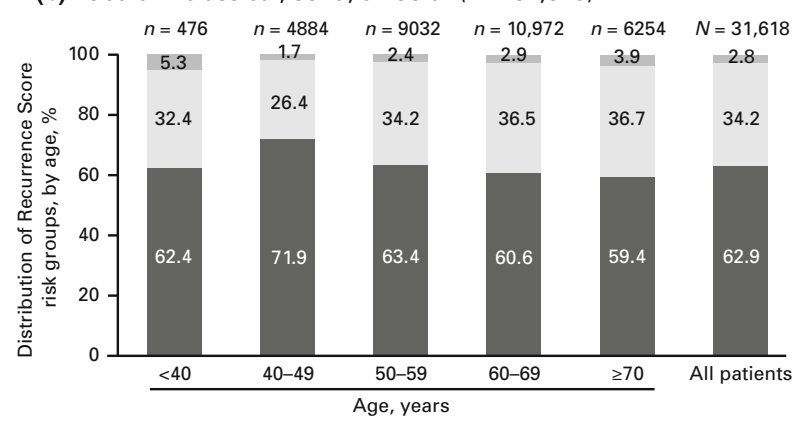

(d) Medullary/medullary-like $(N=1101)$

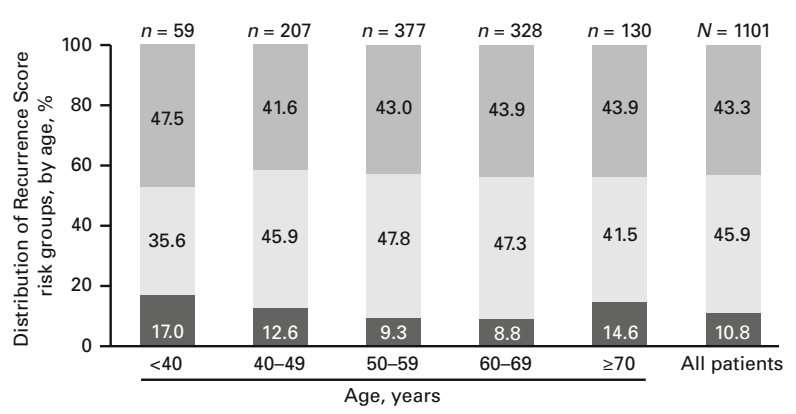

Recurrence Score risk group

High ( $\geq 31$ )

Intermediate (18-30)

- Low $(<18)$

c lobular-pleomorphic (0.6\%); d medullary/medullary-like (0.3\%); e other/unknown (9\%). NOS not otherwise specified

information to Adjuvant Online, irrespective of age. Other reports did not find their gene panel differentially expressed according to age when correcting for intrinsic subtype and other clinicopathologic features (as grade, ER status, and nodal status), leading to the conclusion that treatment should be driven by subtype biology and less influenced by age [40]. Our large series shows that the Recurrence Score result and the expression of invasion and proliferation genes have a similar distribution 
(a) ER by RT-PCR, by age group
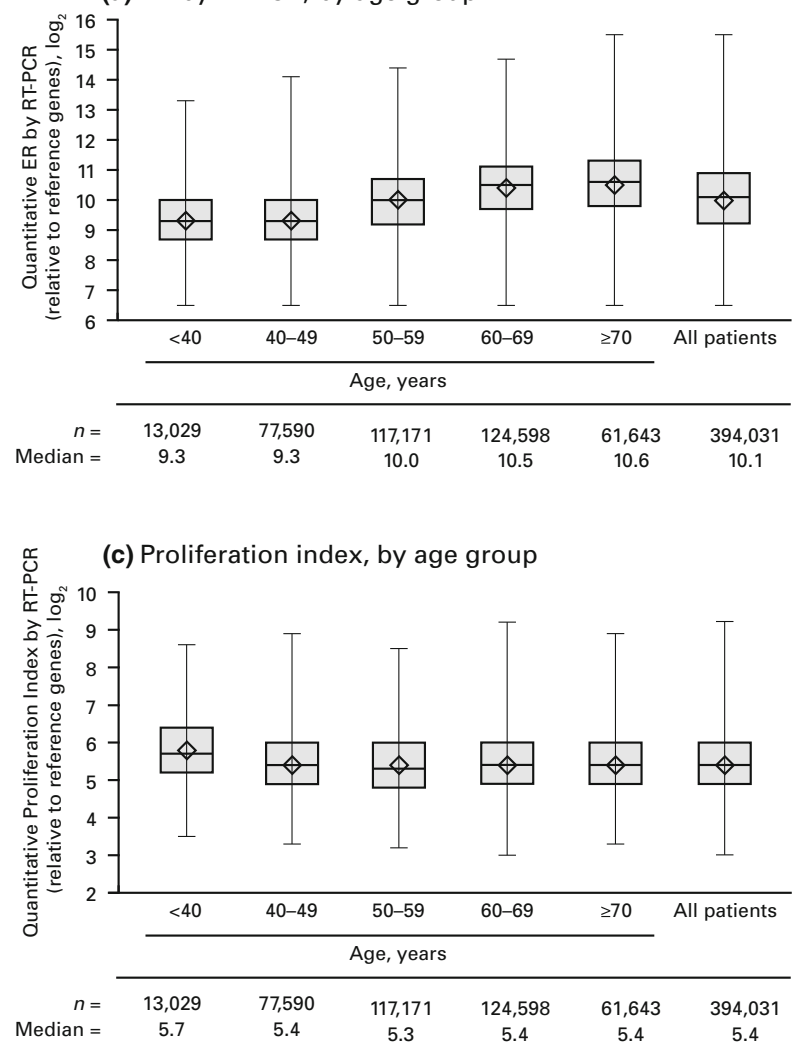

Fig. 6 Comparison of quantitative gene expression scores across age groups ${ }^{\mathrm{a}}$. A wide range of gene expression values were observed within each age group for all gene expression scores. Median ER levels increased with increasing age while median PR levels decreased. Invasion gene group scores and proliferation gene group scores appear similar across the age

in all age groups, again suggesting that age on its own is not necessarily a determinant of more aggressive biologic behavior.

Among the $32,289 \mathrm{~N}+$ patients in our study, there was a wide range of Recurrence Score results (i.e., risk groups) observed in all age groups. This suggests that the patients with $\mathrm{N}+$ disease, across all ages, have tumors with heterogeneous biologic characteristics and prognosis. Our observations of decreasing Recurrence Score values with increasing age (b) PR by RT-PCR, by age group

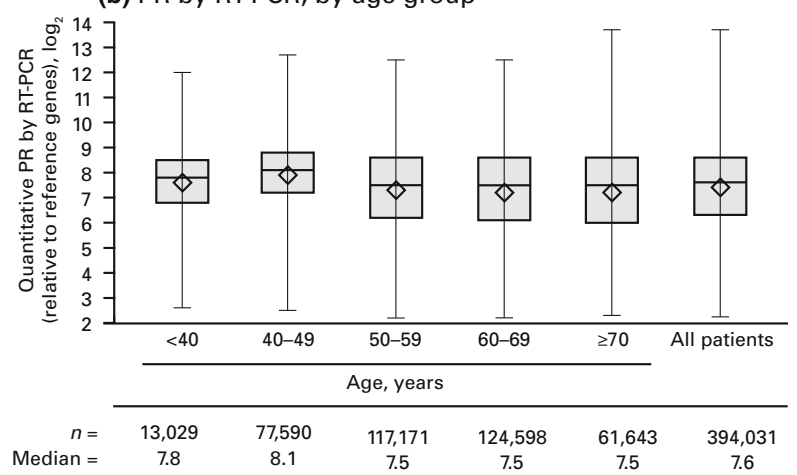

(d) Invasion index, by age group

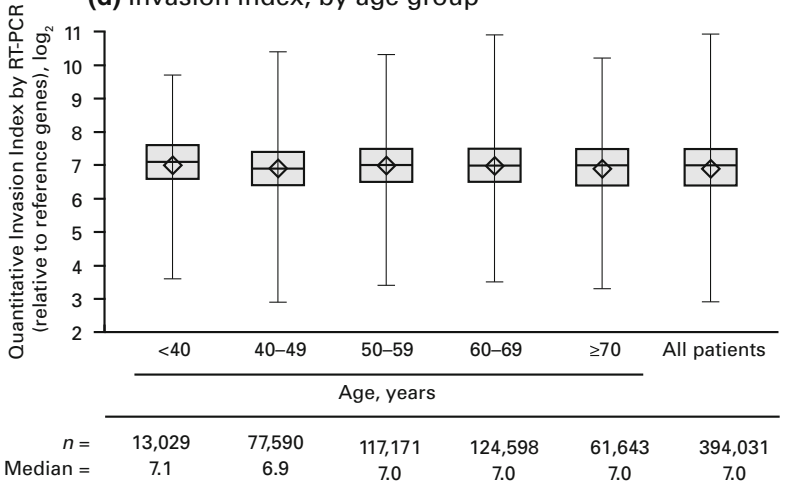

groups. a ER by RT-PCR (+ER $\geq 6.5)$; b PR by RT-PCR $(+P R \geq 5.5)$; $c$ proliferation index; $\mathbf{d}$ invasion index. ${ }^{a}$ Excludes patients with ER-negative tumors $(\mathrm{ER}<6.5$, by RT-PCR). ER estrogen receptor, $P R$ progesterone receptor, $R T-P C R$ reverse transcriptase-polymerase chain reaction

are consistent with prior reports in $\mathrm{N}+$ patients. The prognostic impact of the Recurrence Score result in pre- and post-menopausal $\mathrm{N}+$ women was evaluated in a cohort of the NSABP B28 study, including 1065 patients with positive nodes treated with adjuvant doxorubicin/cyclophosphamide and tamoxifen with or without paclitaxel [41]. In this study, older patients and patients with small tumors were more likely to have a low Recurrence Score result, but the distribution of scores was not 


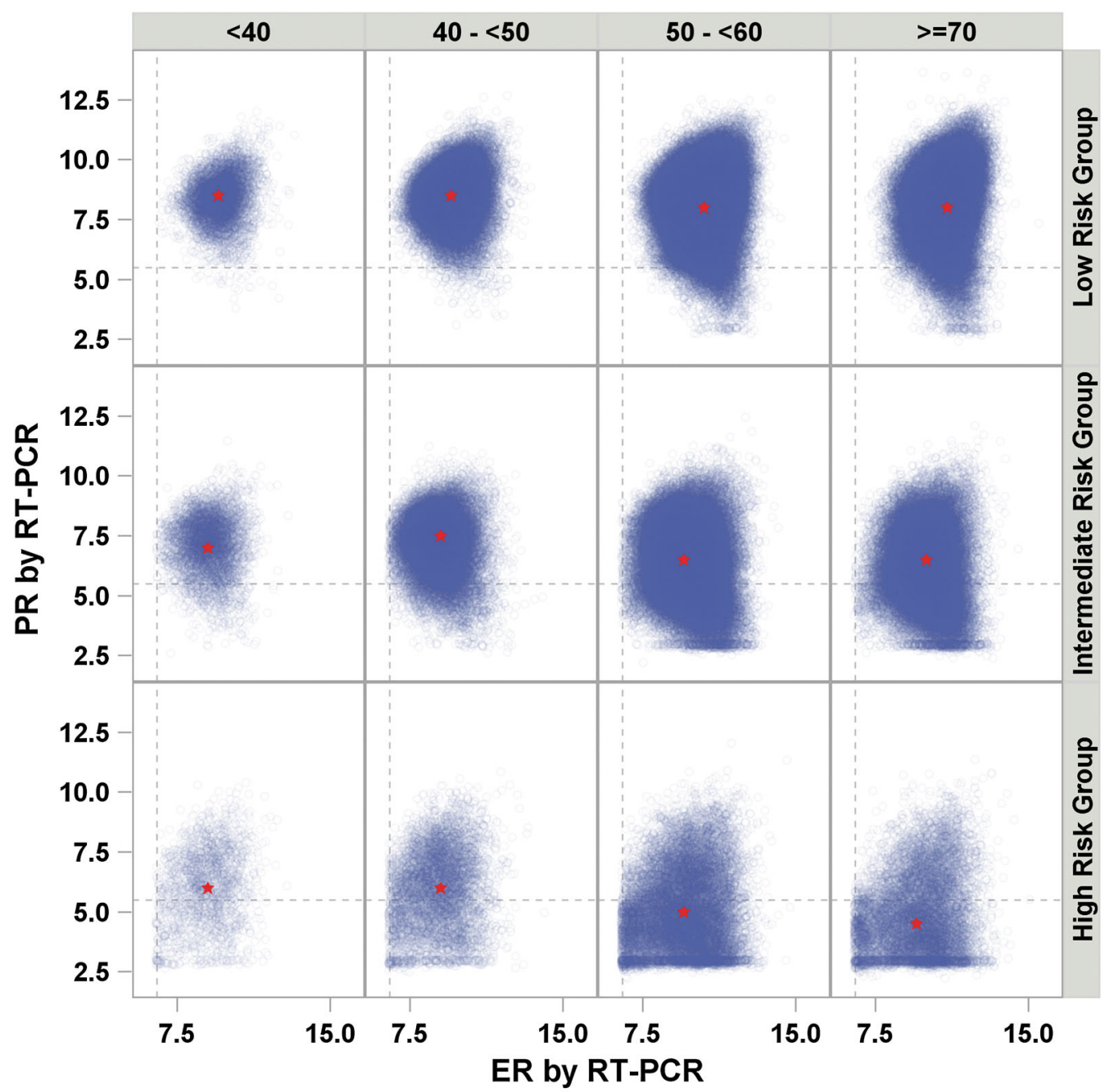

Fig. 7 Quantitative ER and PR expression within age and Recurrence Score risk groups. Joint analysis of ER and PR expression within age and Recurrence Score risk groups shows that a wide and overlapping range of ER and PR expression is observed within age and risk groups. As with

different according to the number of positive nodes. The Recurrence Score result was an independent predictor of distant recurrence beyond age ( $<50$ and $\geq 50$ years), both in women with one to three nodes and in women with four or more nodes involved. Patients with four or more nodes involved with a low score had a better outcome than patients with lower nodal burden but a high score. In addition to its prognostic information, the population as a whole, there is generally an increase in median ER and a decrease in median PR with increasing age. The decrease in PR is most pronounced in high-risk patients. $E R$ estrogen receptor, $P R$ progesterone receptor, $R T-P C R$ reverse transcriptase-polymerase chain reaction

the Recurrence Score result has also been shown to predict the benefit of adding adjuvant chemotherapy to endocrine therapy in a post-menopausal $\mathrm{N}+$ population. In the SWOG S8814 trial, which looked at the addition of chemotherapy to tamoxifen in post-menopausal, $\mathrm{N}+$ patients, the Recurrence Score result was a strong predictive factor of benefit from chemotherapy for disease-free survival [42]. 
Limitations of our analysis include the absence of treatment information, other clinicopathologic characteristics (e.g., size and grade) and importantly, clinical outcomes. However, the consistency in the proportion of patients within each Recurrence Score risk group across the age groups as well as within nodal status and histologic subtypes is consistent with the results from the validation subgroup analysis of NSABP B-14, in which the Recurrence Score result was shown to be prognostic over all age groups [29]. Since we did see a slightly greater proportion of high scores in the younger age group, there is a possibility that breast cancer in young women is enriched with more aggressive subtypes. However, within each age group, breast cancer is heterogeneous and treatment decisions should not be driven by age alone, especially if the biology is favorable.

An additional limitation is a potential for selection bias in that younger women with higher grade tumors or other poor prognostic clinical features would not get tested and therefore be underrepresented. This could impact the overall distribution of scores within the age categories, but should not impact the risk estimates associated with the individual score result, which are derived from controlled studies.

There are currently ongoing trials prospectively evaluating the Recurrence Score result and chemotherapy benefit prediction. Two of the studies, the TAILORx (ClincialTrials.gov identifier, NCT00310180; $N=10,253$ ) and RxPONDER (ClincialTrials.gov identifier, NCT01272037; planned $N=4000$ ) trials in women with ER+ and node-negative or $\mathrm{N}+$ or early breast cancer, respectively, will determine whether the addition of chemotherapy to endocrine therapy is beneficial to patients with a mid-range
Recurrence Score results (11-25 for node-negative and $\leq 25$ for $\mathrm{N}+$ ). Although specific analyses based on age are not planned for the TAILORx and RxPONDER studies, all ages between 18 and 75 years are eligible and given the large sample size of the studies, it can be expected that at least $20 \%$ will be $<50$ years and approximately $10 \%<40$ years based on current demographics, which will allow further opportunities to evaluate the effect of age as a determinant of prognosis within the different Recurrence Score groups.

Recently, the 5-year outcomes of the Study Arm A of TAILORx (Recurrence Score results $<11$ ) treated with hormone therapy alone were reported [43]. Of the 10,253 patients enrolled, 1626 had Recurrence Score results of $<11 ; 430$ (27\%) were $\leq 50$ years and 58 $(4 \%)$ were $\leq 40$ years and were similar in proportion to the Study Arms B/C, which were the randomized arms with scores of 11-25. The 5 -year freedom from distant recurrence estimate was $99.3 \%$ [95\% confidence interval (CI): 98.7-99.6], the 5-year freedom from any recurrence estimate was $98.7 \% \quad(95 \% \quad \mathrm{CI}$ : 97.9-99.2), the disease-free survival was $93.8 \%$ (95\% CI: 92.4-94.9), and OS at 5 years was 98\% (95\% CI: 97.1-98.6). In the multivariate analysis, there was no significant difference in recurrence risk by age ( $\leq 50$ vs. $51-60$ vs. 61-75 years). The clinical significance of the TAILORx Arm A results, as it pertains to this analysis of close to 400,000 patients, is a demonstration that patients with a low Recurrence Score result $(<11)$ treated with appropriate hormone therapy have an excellent outcome, will have little chance of benefitting from addition of chemotherapy, and that age, as a single factor, does not have an impact.

The Recurrence Score result has significantly affected the treatment paradigm for ER+ 
early-stage breast cancer with a shift away from chemotherapy for women with low scores. However, the shift has not been as great in younger women ( $<40$ years). Strengths of this analysis are the size of the dataset with over 390,000 patients, demonstrating consistency of the distribution of Recurrence Score values across age categories, as well as histologic subtype, nodal status, ER/PR expression and the proliferation and invasion index.

\section{CONCLUSIONS}

These results show that the Recurrence Score result reflects tumor biology beyond age alone and has clinical implications for both younger and older patients with respect to optimizing treatment decisions.

\section{ACKNOWLEDGMENTS}

This analysis was funded by Genomic Health, Redwood City, CA, USA. The article processing charges and open access fee for this publication were funded by Genomic Health. All named authors meet the International Committee of Medical Journal Editors (ICMJE) criteria for authorship for this manuscript, take responsibility for the integrity of the work as a whole, and have given final approval for the version to be published. All authors had full access to all of the data in this study and take complete responsibility for the integrity of the data and accuracy of the data analysis. CodonMedical, an Ashfield Company, part of UDG Healthcare plc provided writing, editorial, and graphics support for the development of this manuscript; their participation was funded by Genomic Health. Information in this article has been presented previously, in part, as a poster: Shak S, Baehner
FL, Stein M, Lewis S, Chen I, Yoshizawa C, Watson D, Swain S, et al. Quantitative Gene Expression Analysis in a Large Cohort of Estrogen-Receptor Positive Breast Cancers: Characterization of the Tumor Profiles in Younger Patients (B40 years) and in Older Patients (C70 years). San Antonio Breast Cancer Symposium (SABCS) 2010; San Antonio, TX. Abstract \#P3-10-01.

Disclosures. Carl Yoshizawa, Megan Rothney, and Amy P. Sing are employees of Genomic Health. Sandra M. Swain and Raquel Nunes have nothing to disclose.

Compliance with ethics guidelines. This article does not contain any new studies with human or animal subjects performed by any of the authors.

Open Access. This article is distributed under the terms of the Creative Commons Attribution-NonCommercial 4.0 International License (http://creativecommons.org/licenses/ by-nc/4.0/), which permits any noncommercial use, distribution, and reproduction in any medium, provided you give appropriate credit to the original author(s) and the source, provide a link to the Creative Commons license, and indicate if changes were made.

\section{REFERENCES}

1. American Cancer Society. Breast Cancer Facts \& Figures 2013-2014. Atlanta: American Cancer Society, Inc. 2013. http://www.cancer.org/acs/ groups/content/@research/documents/document/ acspc-042725.pdf. Accessed 31 Aug 2015.

2. Siegel RL, Miller KD, Jemal A. Cancer statistics, 2015. CA Cancer J Clin. 2015;65:5-29.

3. Adami HO, Malker B, Holmberg L, et al. The relation between survival and age at diagnosis in breast cancer. N Engl J Med. 1986;315:559-63. 
4. El Saghir NS, Seoud M, Khalil MK, et al. Effects of young age at presentation on survival in breast cancer. BMC Cancer. 2006;6:194.

5. Bharat A, Aft RL, Gao F, et al. Patient and tumor characteristics associated with increased mortality in young women $(<$ or $=40$ years $)$ with breast cancer. J Surg Oncol. 2009;100:248-51.

6. Howlader N, Noone AM, Krapcho M, et al. SEER Cancer Statistics Review, 1975-2011, National Cancer Institute. Bethesda, MD, http://seer.cancer. gov/csr/1975_2011/, based on November 2013 SEER data submission, posted to the SEER web site, April 2014. Accessed 5 Jan 2015.

7. Nixon AJ, Neuberg D, Hayes DF, et al. Relationship of patient age to pathologic features of the tumor and prognosis for patients with stage I or II breast cancer. J Clin Oncol. 1994;12:888-94.

8. Gnerlich JL, Deshpande AD, Jeffe DB, et al. Elevated breast cancer mortality in women younger than age 40 years compared with older women is attributed to poorer survival in early-stage disease. J Am Coll Surg. 2009;208:341-7.

9. Kheirelseid EH, Boggs JM, Curran C, et al. Younger age as a prognostic indicator in breast cancer: a cohort study. BMC Cancer. 2011;11:383.

10. Lin NU, Vanderplas A, Hughes ME, et al. Clinicopathologic features, patterns of recurrence, and survival among women with triple-negative breast cancer in the National Comprehensive Cancer Network. Cancer. 2012;118:5463-72.

11. Partridge $\mathrm{AH}$, Hughes ME, Ottesen RA, et al. The effect of age on delay in diagnosis and stage of breast cancer. Oncologist. 2012;17:775-82.

12. Fredholm H, Eaker S, Frisell J, et al. Breast cancer in young women: poor survival despite intensive treatment. PLoS One. 2009;4:e7695.

13. National Comprehensive Cancer Network. NCCN clinical practice guidelines in oncology (NCCN Guidelines): Breast Cancer (Version 3.2014). http://www.nccn.org/professionals/physician_gls/ f_guidelines.asp\#site. Accessed 5 Jan 2015.

14. Burstein HJ, Prestrud AA, Seidenfeld J, et al. American Society of Clinical Oncology clinical practice guideline: update on adjuvant endocrine therapy for women with hormone receptor-positive breast cancer. J Clin Oncol. 2010;28:3784-96.

15. Goldhirsch A, Winer EP, Coates AS, et al. Personalizing the treatment of women with early breast cancer: highlights of the St Gallen International Expert Consensus on the Primary
Therapy of Early Breast Cancer 2013. Ann Oncol. 2013;24:2206-23.

16. Senkus E, Kyriakides S, Penault-Llorca F, et al. Primary breast cancer: ESMO Clinical Practice Guidelines for diagnosis, treatment and follow-up. Ann Oncol. 2013;24(Suppl 6):vi7-23.

17. National Institute for Health and Care Excellence (NICE). NICE Diagnostics Guidance 10 (September 2013): Gene expression profiling and expanded immunohistochemistry tests for guiding adjuvant chemotherapy decisions in early breast cancer management: MammaPrint, Oncotype DX, IHC4, and Mammostrat. www.nice.org.uk/dg10. Accessed 5 Jan 2015.

18. Swain SM, Whaley FS, Ewer MS. Congestive heart failure in patients treated with doxorubicin: a retrospective analysis of three trials. Cancer. 2003;97:2869-79.

19. Pinder MC, Duan Z, Goodwin JS, et al. Congestive heart failure in older women treated with adjuvant anthracycline chemotherapy for breast cancer. J Clin Oncol. 2007;25:3808-15.

20. Zambetti M, Moliterni A, Materazzo C, et al. Long-term cardiac sequelae in operable breast cancer patients given adjuvant chemotherapy with or without doxorubicin and breast irradiation. J Clin Oncol. 2001;19:37-43.

21. Bonneterre J, Roche $\mathrm{H}$, Kerbrat $\mathrm{P}$, et al. Long-term cardiac follow-up in relapse-free patients after six courses of fluorouracil, epirubicin, and cyclophosphamide, with either 50 or $100 \mathrm{mg}$ of epirubicin, as adjuvant therapy for node-positive breast cancer: French adjuvant study group. J Clin Oncol. 2004;22:3070-9.

22. Ganz PA, Hussey MA, Moinpour CM, et al. Late cardiac effects of adjuvant chemotherapy in breast cancer survivors treated on Southwest Oncology Group protocol s8897. J Clin Oncol. 2008;26:1223-30.

23. Azim HA Jr, de Azambuja E, Colozza M, et al. Long-term toxic effects of adjuvant chemotherapy in breast cancer. Ann Oncol. 2011;22:1939-47.

24. Tallman MS, Gray R, Bennett JM, et al. Leukemogenic potential of adjuvant chemotherapy for early-stage breast cancer: the Eastern Cooperative Oncology Group experience. J Clin Oncol. 1995;13:1557-63.

25. Smith RE, Bryant J, DeCillis A, et al. Acute myeloid leukemia and myelodysplastic syndrome after doxorubicin-cyclophosphamide adjuvant therapy for operable breast cancer: the National Surgical Adjuvant Breast and Bowel Project Experience. J Clin Oncol. 2003;21:1195-204. 
26. Conroy SK, McDonald BC, Smith DJ, et al. Alterations in brain structure and function in breast cancer survivors: effect of post-chemotherapy interval and relation to oxidative DNA damage. Breast Cancer Res Treat. 2013;137:493-502.

27. Falleti MG, Sanfilippo A, Maruff P, et al. The nature and severity of cognitive impairment associated with adjuvant chemotherapy in women with breast cancer: a meta-analysis of the current literature. Brain Cogn. 2005;59:60-70.

28. Badve SS, Baehner FL, Gray RP, et al. Estrogen- and progesterone-receptor status in ECOG 2197: comparison of immunohistochemistry by local and central laboratories and quantitative reverse transcription polymerase chain reaction by central laboratory. J Clin Oncol. 2008;26:2473-81.

29. Paik S, Shak S, Tang G, et al. A multigene assay to predict recurrence of tamoxifen-treated, node-negative breast cancer. $\mathrm{N}$ Engl J Med. 2004;351:2817-26.

30. Dinan MA, Mi X, Reed SD, et al. Initial trends in the use of the 21-gene recurrence score assay for patients with breast cancer in the Medicare population, 2005-2009. JAMA Oncol. 2015;1:158-66.

31. Chen C, Dhanda R, Tseng WY, et al. Evaluating use characteristics for the oncotype $d x$ 21-gene recurrence score and concordance with chemotherapy use in early-stage breast cancer. J Oncol Pract. 2013;9:182-7.

32. Eiermann W, Rezai M, Kümmel S, et al. The 21-gene recurrence score assay impacts adjuvant therapy recommendations for ER-positive, node-negative and node-positive early breast cancer resulting in a risk-adapted change in chemotherapy use. Ann Oncol. 2013;24:618-24.

33. Paik S, Tang G, Shak S, et al. Gene expression and benefit of chemotherapy in women with node-negative, estrogen receptor-positive breast cancer. J Clin Oncol. 2006;24:3726-34.

34. Dowsett M, Cuzick J, Wale C, et al. Prediction of risk of distant recurrence using the 21-gene Recurrence Score in node-negative and node-positive postmenopausal patients with breast cancer treated with anastrozole or tamoxifen: a TransATAC Study. J Clin Oncol. 2010;28:1829-34.
35. Mamounas EP, Tang G, Paik S, et al. Prognostic impact of the 21-gene recurrence score (RS) on disease-free and overall survival of node-positive, ER-positive breast cancer patients (pts) treated with adjuvant chemotherapy: Results from NSABP B-28. J Clin Oncol. 2012;30 (Suppl 27): abs 1.

36. Gnant M, Dowsett M, Filipits M, et al. Identifying clinically relevant prognostic subgroups in node-positive postmenopausal $\mathrm{HR}+$ early breast cancer patients treated with endocrine therapy: a combined analysis of 2485 patients from ABCSG-8 and ATAC using the PAM50 risk of recurrence (ROR) score and intrinsic subtype. J Clin Oncol. 2013;31 (Suppl): abs 506.

37. Liebermann N, Baehner FL, Soussan-Gutman L, et al. Evaluation of recurrence score and traditional clinicopathologic assessments in a large ER-positive, lymph node-negative patient cohort. J Clin Oncol. 2011;29 (Suppl): abs 632.

38. SEER Cancer Statistics Factsheets: Breast Cancer. National Cancer Institute. Bethesda, MD. http:// seer.cancer.gov/statfacts/html/breast.html. Accessed 6 Jan 2015.

39. Azim HA Jr, Michiels S, Bedard PL, et al. Elucidating prognosis and biology of breast cancer arising in young women using gene expression profiling. Clin Cancer Res. 2012;18:1341-51.

40. Anders CK, Hsu DS, Broadwater G, et al. Young age at diagnosis correlates with worse prognosis and defines a subset of breast cancers with shared patterns of gene expression. J Clin Oncol. 2008;26:3324-30.

41. Mamounas EP, Bryant J, Lembersky B, et al. Paclitaxel after doxorubicin plus cyclophosphamide as adjuvant chemotherapy for node-positive breast cancer: results from NSABP B-28. J Clin Oncol. 2005;23:3686-96.

42. Albain K, Barlow W, Shak S, et al. Prognostic and predictive value of the 21-gene recurrence score assay in postmenopausal women with node-positive, oestrogen-receptor-positive breast cancer on chemotherapy: a retrospective analysis of a randomised trial. Lancet Oncol. 2010;11:55-65.

43. Sparano JA, Gray RJ, Makower DF, et al. Prospective Validation of a 21-Gene Expression Assay in Breast Cancer. N Engl J Med. 2015 Sep 27. [Epub ahead of print]. 